\title{
Experimental and Theoretical Investigations on the Corrosion Inhibition action of Thiadiazole Derivatives on Carbon Steel in $1 \mathrm{M} \mathrm{HCl}$ medium
}

\section{REEJA JOHNSON ${ }^{1}$, JOBY THOMAS KAKKASSERY ${ }^{2 *}$, VINOD RAPHAEL PALAYOOR ${ }^{3}$, RAGI KOOLIYAT ${ }^{4}$ and VIDHYA THOMAS KANNANAIKKAL ${ }^{5}$}

\author{
${ }^{1,2,4,5}$ Centre for Electrochemical Studies, St. Thomas' College (Autonomous), Thrissur, \\ (University of Calicut), Kerala-680001, India. \\ ${ }^{3}$ Department of Chemistry, Government Engineering College, Thrissur, Kerala-680009, India. \\ *Corresponding author E-mail: drjobythomask@gmail.com
}

http://dx.doi.org/10.13005/ojc/360624

(Received: October 17, 2020; Accepted: November 23, 2020)

\begin{abstract}
Novel thiadiazole derivatives of Schiff bases namely (E)-N-(anthracen-9-ylmethylene)5-(4-nitrophenyl)-1,3,4-thiadiazol-2-amine (A9CNPTDA) and N-(anthracen-9(10H)-ylidene)5-(4-nitrophenyl)-1,3,4-thiadiazol-2-amine (ANNPTDA) were synthesized, characterized and corrosion inhibition behaviour, as well as the mechanism of inhibition were investigated by different monitoring techniques like gravimetric measurements, electrochemical impedance spectroscopy, potentiodynamic polarization, quantum chemical and SEM studies. Both of the thiadiazole derivatives showed excellent corrosion inhibitor action on carbon Steel in acid medium. A9CNPTDA exhibited highest inhibition efficiency of $98.04 \%$ at $1 \mathrm{mM}$ concentration while ANNPTDA showed a maximum of 95.32\%. In HCl medium, both derivatives obeyed Langmuir adsorption isotherm and thermodynamic parameters $\left(\mathrm{K}_{\mathrm{ads}}, \Delta \mathrm{G}^{0}{ }_{\text {ads }}\right)$ were calculated. An acceptable relationship was observed between the results of quantum chemical calculations and other corrosion monitoring analysis.
\end{abstract}

Keywords: Corrosion inhibition, Schiff bases, Thiadiazoles, Potentiodynamic polarization, Electrochemical impedance, Adsorption Isotherm.

\section{INTRODUCTION}

The acidic solutions are usually used in metal industries for de-scaling, acid pickling, cleaning process and presence of these corrosive media are the foremost reasons for the increase in the rate of metallic dissolution. The exploitation of assured organic compounds as inhibitors is the most practical method to prevent corrosion of the
Carbon Steel (CS) in acidic media ${ }^{1,2}$. Compounds with $\pi$-bonds generally exhibit marked inhibitive properties due to the interaction of $\pi$-orbital with the metal surface ${ }^{3-6}$. Most of the well-known acid inhibitors in acid are organic compounds holding sulphur, oxygen and nitrogen atoms. The effectiveness of these molecules mainly depends on their ability to get adsorbed on the surface of metal particularly through polar groups. Significant

This is an Open Access article licensed under a Creative Commons license: Attribution 4.0 International (CC- BY). Published by Oriental Scientific Publishing Company @ 2018

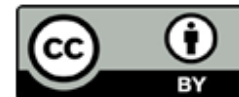


amount of effort is devoted to develop efficient and novel corrosion inhibitors, in recent years ${ }^{7-10}$. Various compounds containing nitrogen, sulphur, and/or oxygen, especially certain thiadiazole derivatives have attracted more and more attention in this area. The present investigation was undertaken to examine the corrosion inhibition efficiencies of two novel thiadiazole derivatives, A9CNPTDA and ANNPTDA derived from anthracene-9-carbaldehyde and anthrone, on carbon steel using gravimetric weight loss measurements, potentiodynamic polarization, electrochemical impedance spectroscopy (EIS), quantum chemical and SEM studies. The corrosion inhibition mechanism was confirmed by adsorption and surface morphology analysis. Quantumchemical investigations on corrosion inhibition using Gammess software were also performed.

\section{MATERIALS AND METHODS}

\section{Inhibitor and solutions}

All chemicals (Sigma-Aldrich) and absolute ethanol $\left(\mathrm{C}_{2} \mathrm{H}_{5} \mathrm{OH}\right.$, Fisher, 99.9\%) were used as received. The azomethine compound was synthesized and characterized through their spectral data. The aggressive solutions of $1 \mathrm{M} \mathrm{HCl}$ was prepared by using standard grade $\mathrm{HCl}$ (Merck) and deionized water. Inhibitor solutions were prepared in the range, $0.2 \mathrm{mM}^{-1} \mathrm{Mm}$ concentrations.

\section{Synthesis and Characterization}

Polynuclear Schiff base, (E)-N-(anthracen9-ylmethylene)-5-(4-nitrophenyl)-1,3,4-thiadiazol-2amine (A9CNPTDA) was synthesized by adding a hot ethanolic solution of anthracene-9-carbaldehyde $(2 \mathrm{mM})$ in dropwise to stirred solution containing equimolar concentration of 5-(4-nitrophenyl)-1,3,4thiadiazol-2-amine in ethanol medium. The mixture was refluxed for $4 \mathrm{hr}$, cooled and concentrated to derive orange coloured needle-shaped crystals of A9CNPTDA.m.p 2790C (Yield: 73\%).

Heterocyclic Schiff base N-(anthracen9(10H)-ylidene)-5-(4-nitrophenyl)-1,3,4-thiadiazol2-amine (ANNPTDA) was synthesized by the condensation of equimolar mixture of 5-(4-nitrophenyl)1,3,4-thiadiazol-2-amine and anthrone in ethanol medium. The reaction mixture was refluxed for $4 \mathrm{~h}$ concentrated and cooled. Offwhite coloured crystals of ANNPTDA separated was filtered, washed and dried and m.p $210^{\circ} \mathrm{C}$ (Yield: $75 \%$ )
Schematic representation of the synthesis of Schiff bases (A9CNPTDA and ANNPTDA) are shown in Fig. 1. Synthesized products were characterized by elemental analysis as well as electronic, FTIR, Mass and NMR Spectral studies with aid of Shimadzu UV-Visible-1800(DMSO), Shimadzu IR-Affinity-1, Shimadzu, QP 2010 GCMS and BrukerAvance III HD respectively.

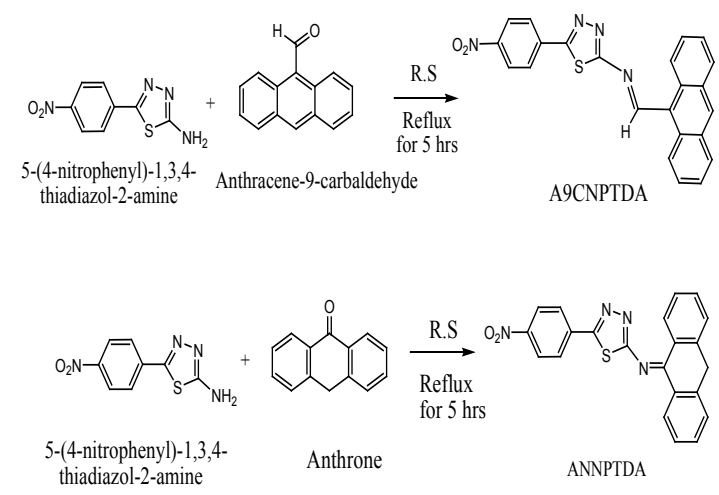

Fig. 1. Schematic representation of synthesis of Schiff bases A9CNPTDA and ANNPTDA

\section{Gravimetric Studies}

Carbon steel coupons were cut and abraded with various grades of SiC papers (100, 220, 400, 600, 800, 1000, 1500 and 2000) washed with distilled water followed by acetone. Approximate composition of the steel specimen was determined by EDAX technique $(0.55 \% \mathrm{C}, 0.08 \% \mathrm{Mn}, 0.04 \%$ $\mathrm{P}, 0.012 \% \mathrm{~S}, 0.02 \% \mathrm{Si}$, and $\mathrm{Fe}$ the rest using Hitachi SU6600 model SEM. Stock solutions of A9CNPTDA and ANNPTDA ( $1 \mathrm{mM})$ in $1 \mathrm{M} \mathrm{HCl}$ were prepared and diluted to get different concentrations $(0.2-1 \mathrm{mM})$.

The metal specimens were immersed in the aggressive medium for 5 days at $28 \pm 0.1^{\circ} \mathrm{C}$ with a periodical evaluation of the corrosion rate. The experiments were carried out in duplicate and the average values were reported. The rate of corrosion was determined by ${ }^{11,12}$

$$
v=\frac{\mathrm{K} \times \mathrm{W}}{\mathrm{DSt}}
$$

Where $v=$ corrosion rate $(m m y-1), W=$ weight loss $(\mathrm{g}), \mathrm{S}=$ surface area of metal specimen $\left(\mathrm{cm}^{2}\right)$, $t=$ time of treatment $(\mathrm{h}), D=$ density of specimen $\left(\mathrm{gcm}^{-3}\right)$, and $K=$ a constant $\left(8.76 \times 10^{4}\right)$. The inhibition efficiency (\%) was obtained by the following equation:

$$
\eta=\frac{v-v^{\prime}}{v} \times 100
$$


Where $v \& v$ ' are the corrosion rate of the metal specimen in the absence and presence of the inhibitor, respectively.

\section{Effect of Temperature}

The effect of temperature on corrosion was evaluated by the gravimetric weight loss studies at the temperature range $30-60^{\circ} \mathrm{C}$. Arrheniusequation ${ }^{13}$ was used for the calculation of the activation energy of corrosion with and without inhibitors which is given by,

$$
\mathrm{K}=\mathrm{A} \exp \left(\frac{-E a}{R T}\right)
$$

Where $K$ is the rate of corrosion, $A$ the frequency factor, $E_{a}$ the activation energy and $T$ the temperature in Kelvin and $\mathrm{R}$ is the gas constant. Arrhenius curves were obtained by plotting logK against $1000 / T$. Enthalpy and entropy of activation $\left(\Delta H^{*}\right.$, $\left.\Delta S^{*}\right)$ were calculated from the transition state theory, which can be represented by the following equation.

$$
K=\left(\frac{R T}{N h}\right) \exp \left(\frac{\Delta S *}{R}\right) \exp \left(\frac{-\Delta H *}{R T}\right)
$$

\section{Electrochemical Studies}

Electrochemical studies were executed using three-electrode cell assembly consisting of CS as working electrode (exposed area $1 \mathrm{~cm}^{2}$ ), platinum electrode as counter electrode $\left(1 \mathrm{~cm}^{2}\right)$ and saturated calomel electrode (SCE) as reference electrode at $28^{\circ} \mathrm{C}$. For acid corrosion, the working area of metal specimens was made to contact with the electrolyte for 30 min preceding the experiment. Ivium Compactstat-e electrochemical system together with Iviumsoft software package was used to perform the experiments.

\section{Electrochemical Impedance Spectroscopic Studies (EIS)}

EIS measurements were taken at the constant potential in the frequency range from $1 \mathrm{KHz}$ to $100 \mathrm{mHz}$ with an amplitude of $10 \mathrm{mV}$ as excitation signal. The percentage of inhibition was calculated by the equation. ${ }^{14}$

$$
\eta_{\mathrm{EIS}} \%=\frac{\mathrm{R}_{\mathrm{ct}}-\mathrm{R}_{\mathrm{ct}}^{\prime}}{\mathrm{R}_{\mathrm{ct}}} \times 100
$$

Where $\mathrm{R}_{\mathrm{ct}}$ and $\mathrm{R}_{\mathrm{ct}}$ are the charge transfer resistances of the working electrode in the presence and absence of inhibitor, respectively.

\section{Potentiodynamic Polarization Studies}

Polarization studies were carried out by altering the potential of working electrode from +250 to $-250 \mathrm{mV}$ with a sweep rate of $1 \mathrm{mV} / \mathrm{s}^{15}$. Slope analysis of Tafel curves gave the corrosion current densities and the inhibition efficiency $\left(\eta_{\text {pol }} \%\right)$ was calculated.

$$
\eta_{\text {pol }} \%=\frac{I_{\text {corr }}-I_{\text {corr }}^{\prime}}{I_{\text {corr }}} \text { X100 }
$$

Where $\mathrm{I}_{\text {corr }}$ and $\mathrm{I}_{\text {corr }}$ are corrosion current densities of the working electrode in the absence and presence of inhibitors, respectively.

\section{Surface Morphological Studies}

Scanning Electron Microscope images were recorded using Hitachi SU6600 model scanning electron microscope, after treatment with $1 \mathrm{M} \mathrm{HCl}$ solution with and without the inhibitors, for 24 hours.

\section{Quantum Chemical Studies}

GAMMES software and DFT method were employed for the determination of optimized geometry of compounds and quantum chemical evaluations. A combination of Lee-Yang-Parr nonlocal correlation functional (B3LYP) and Beck's three-parameter exchange functional were employed in DFT method ${ }^{16-18}$.

\section{RESULTS AND DISCUSSION}

The structures of inhibitor molecules synthesized were confirmed by spectroscopic and elemental data.

\section{$\mathrm{N}$-(anthracen-9-ylmethylene)-5-(4-nitrophenyl)-} 1,3,4-thiadiazol-2-amine (A9CNPTDA)

Anal.calcd. for $\mathrm{C}_{23} \mathrm{H}_{14} \mathrm{~N}_{4} \mathrm{O}_{2} \mathrm{~S}$ : C, 67.30; $\mathrm{H}$, 3.44; N, 13.65; O, 7.8; S, 7.81\%. Found: C, 66.72; H, 3.31 ; N, 13.58; O, 7.5; S, 7.75\%. IR(KBr); $1691 \mathrm{~cm}^{-1}$ $(\mathrm{C}=\mathrm{N}), 3102 \mathrm{~cm}^{-1}(\mathrm{C}-\mathrm{H}), 1556$ and $1445 \mathrm{~cm}^{-1}(\mathrm{C}=\mathrm{C})$, $1527 \mathrm{~cm}^{-1}, 1347 \mathrm{~cm}^{-1}\left(\mathrm{NO}_{2}\right), 1274 \mathrm{~cm}^{-1}(\mathrm{C}-\mathrm{N}), 1104$ $\mathrm{cm}^{-1}(\mathrm{C}-\mathrm{S})$, UV; $39062 \mathrm{~cm}^{-1}\left(\pi \rightarrow \pi^{\star}\right), 27100 \mathrm{~cm}^{-1}$ $\left(\mathrm{n} \rightarrow \pi^{\star}\right),{ }^{1} \mathrm{HNMR} ; \delta \mathrm{CH}=\mathrm{N} 11.5(\mathrm{~s}), \delta \mathrm{NH} 12.0(\mathrm{br})$, $\delta \mathrm{CH}$ in aromatic rings 7.75- 9.03(m). ${ }^{13} \mathrm{C} N M R$; 136ppm $(\mathrm{C}=\mathrm{N})$, 123-154ppm (aromatic $\mathrm{C})$. EIMS; $\mathrm{m} / \mathrm{z} 222$ (base peak), $\left[\mathrm{C}_{8} \mathrm{H}_{6} \mathrm{~N}_{4} \mathrm{O}_{2} \mathrm{~S}\right]^{+}, 163\left[\mathrm{C}_{8} \mathrm{H}_{7} \mathrm{~N}_{2} \mathrm{~S}\right]^{+}$, $120\left[\mathrm{C}_{7} \mathrm{H}_{4} \mathrm{~S}\right]+, \mathrm{m} / \mathrm{z} 91\left[\mathrm{C}_{7} \mathrm{H}_{7}\right]^{+}$and $74\left[\mathrm{CH}_{2} \mathrm{~N}_{2} \mathrm{~S}\right]^{+}$.

$\mathrm{N}$-(anthracen-9(10H)-ylidene)-5-(4-nitrophenyl)1,3,4-thiadiazol-2-amine (ANNPTDA)

Anal.calcd. for $\mathrm{C}_{22} \mathrm{H}_{14} \mathrm{~N}_{4} \mathrm{O}_{2} \mathrm{~S}$ : C, 66.32; $\mathrm{H}$, 
3.54; N, 14.06; O, 8.03; S,8.05\%. Found: C, 65.72; $\mathrm{H}, 3.38 ; \mathrm{N}, 13.84 ; \mathrm{O}, 7.4 ; \mathrm{S}, 7.95 \%$. IR(KBr); 1662 $\mathrm{cm}^{-1}(\mathrm{C}=\mathrm{N}), 3066 \mathrm{~cm}^{-1}(\mathrm{C}-\mathrm{H}), 1597,1510 \mathrm{~cm}^{-1}(\mathrm{C}=\mathrm{C})$, $1317,1400 \mathrm{~cm}^{-1}\left(\mathrm{NO}_{2}\right), 1166 \mathrm{~cm}^{-1}(\mathrm{C}-\mathrm{N}), 1101 \mathrm{~cm}^{-1}$ (C-S), UV; $39062 \mathrm{~cm}^{-1}, 37453 \mathrm{~cm}^{-1}\left(\pi \rightarrow \pi^{\star}\right), 27174$ $\mathrm{cm}^{-1}\left(\mathrm{n} \rightarrow \pi^{*}\right),{ }^{1} \mathrm{HNMR} ; \delta \mathrm{CH} 24.3(\mathrm{~s}), \delta \mathrm{CH}$ in aromatic rings $7.34-8.32(\mathrm{~m}) .{ }^{13} \mathrm{C}$ NMR; $123-164 \mathrm{ppm}$ (18 different aromatic sp $\mathrm{C}^{2}$ atoms). EIMS; $\mathrm{m} / \mathrm{z} 194$ (base peak), $\left[\mathrm{C}_{14} \mathrm{H}_{12} \mathrm{~N}\right]^{+}, 165\left[\mathrm{C}_{8} \mathrm{H}_{9} \mathrm{~N}_{2} \mathrm{~S}\right]^{+}$.

Molecular structures and optimized geometries of A9CNPTDA and ANNPTDA are given in the Figure 2.
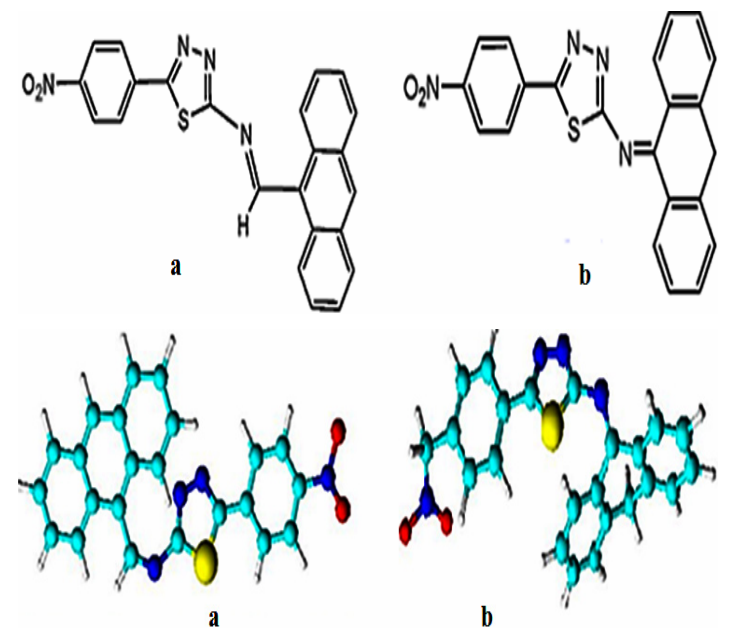

Fig. 2. Molecular structures and Optimised geometries of Schiff bases, a) A9CNPTDA and b) ANNPTDA

\section{Gravimetric Corrosion Inhibition Studies}

The corrosion inhibition efficiencies of two molecules A9CNPTDAand ANNPTDA for $24 \mathrm{~h}$ at $\left(28 \pm 0.1^{\circ} \mathrm{C}\right)$ are listed in Table 1 . Both molecules displayed excellent inhibition efficiency on CS surface, maybe due to the presence of highly polarizable sulphur atom and nitrogen atom in the thiadiazole ring. Presence of azomethine linkage and aromatic rings increases its inhibition efficiency even at very low concentration. For a period of $24 \mathrm{~h}$, A9CNPTDA showed higher inhibition efficiency than ANNPTDA. The remarkable corrosion preventing ability of A9CNPTDA may be attributed to the presence of highly conjugated azomethine linkage and planarity of the molecule. In addition to this highly delocalized $\pi$ electron cloud of the aromatic ring increases its inhibition efficiency. Even though there is a structural similarity between A9CNPTDA and ANNPTDA, corrosion inhibition efficiency of ANNPTDA is relatively low, compared to that of
A9CNPTDA which may be due to the deviation from coplanarity of the molecule. Presence of strained azomethine linkage and less aromatic nature in the molecule also decrease its inhibition efficiency.

Table 1: Gravimetric corrosion inhibition efficiencies (\%) of A9CNPTDA and ANNPTDA on CS in $1 \mathrm{M} \mathrm{HCl}$ for $24 \mathrm{hr}$ at $28 \pm 0.1^{\circ} \mathrm{C}$

\begin{tabular}{ccc}
\hline Conc. $(\mathrm{mM})$ & A9CNPTDA & ANNPTDA \\
\hline 0.2 & 93.87 & 81.68 \\
0.4 & 94.26 & 87.16 \\
0.6 & 95.42 & 89.98 \\
0.8 & 96.17 & 91.51 \\
1.0 & 98.04 & 95.32 \\
\hline
\end{tabular}

Figure 3 represents the variation of corrosion inhibition efficiency with time for the inhibitor molecules at $1 \mathrm{mM}$ concentration. The plot reveals that the decrease of $\eta_{w} \%$ for A9CNPTDA was very much steeper than that of ANNPTDA as the days went on. This may be due to excellent adsorption of these molecules on the metal surface because of the presence of highly active heteroatoms and slow hydrolysis rate of A9CNPTDA molecules in acidic medium. The azomethine linkage $(\mathrm{C}=\mathrm{N})$ present in the molecule is susceptible to hydrolysis. The stability of the inhibitor in the aggressive medium is very important if it is to be recommended for long time use. From the results of gravimetric corrosion studies, one can reach into the conclusion that A9CNPTDA molecule acts as an excellent corrosion inhibitor for a long time.

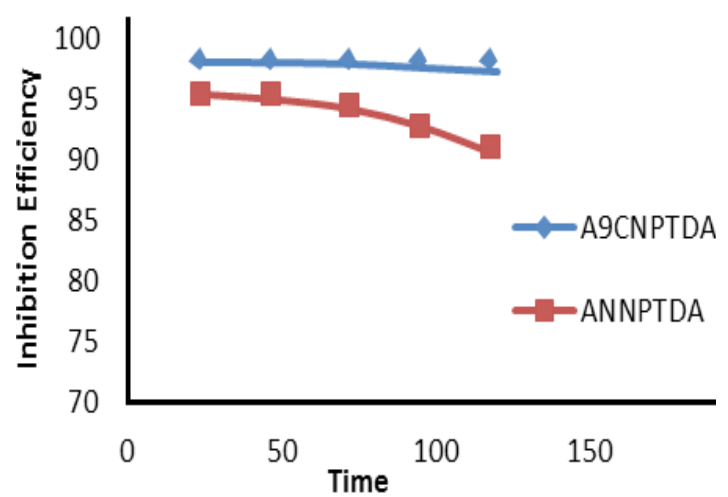

Fig. 3. Variation of corrosion inhibition efficiencies of A9CNPTDA and ANNPTDA (1 $\mathrm{mM}$ ) with time on CS in $1 \mathrm{MHCl}$

\section{Effect of Temperature}

It is apparent from the results that activation energy of dissolution of metal increased with inhibitor concentration. Table 2 explores the activation energy and thermodynamic parameters of corrosion of CS in $1 \mathrm{M} \mathrm{HCl}$ in the presence and absence of A9CNPTDA and ANNPTDA respectively. 
Table 2: Thermodynamic parameters of CS corrosion, in the presence and absence of Schiff base inhibitors, A9CNPTDA and ANNPTDA in $1 \mathrm{M} \mathrm{HCl}$

\begin{tabular}{cccccc}
\hline Inhibitors & $\begin{array}{c}\mathrm{C} \\
(\mathrm{mM})\end{array}$ & $\begin{array}{c}\mathrm{Ea} \\
\left.(\mathrm{kJ} \mathrm{mol})^{-1}\right)\end{array}$ & $\mathrm{A}$ & $\begin{array}{c}\Delta \mathrm{H}^{*} \\
\left(\mathrm{~kJ} \mathrm{~mol}^{-1}\right)\end{array}$ & $\begin{array}{c}\Delta \mathrm{S}^{*} \\
\left(\mathrm{~J} \mathrm{~mol}-1 \mathrm{~K}^{-1}\right)\end{array}$ \\
\hline & Blank & 51.33 & $8.73 \times 10^{9}$ & 48.7 & -56.51 \\
& 0.2 & 109.23 & $1.48 \times 10^{19}$ & 107 & 107.29 \\
& 0.4 & 117 & $2.34 \times 10^{20}$ & 114 & 110.16 \\
A9CNPTDA & 0.6 & 128.7 & $1.91 \times 10^{22}$ & 126 & 113.04 \\
& 0.8 & 132 & $8.71 \times 10^{22}$ & 130 & 121.26 \\
\hline & 1.0 & 140 & $1.2 \times 10^{24}$ & 138 & 133.33 \\
& 0.2 & 94.45 & $6.46 \times 10^{16}$ & 91.8 & 75.12 \\
& 0.4 & 97.57 & $2.0 \times 10^{17}$ & 94.9 & 84.51 \\
ANNPTDA & 0.6 & 102.82 & $1.38 \times 10^{18}$ & 100 & 100.39 \\
& 0.8 & 109.1 & $1.39 \times 10^{19}$ & 106 & 119.55 \\
& 1.0 & 116.83 & $2.69 \times 10^{20}$ & 117 & 142.71 \\
\hline
\end{tabular}

Positive signs of enthalpies with a regular rise reflect the endothermic nature of dissolution and the increasing difficulty of corrosion with the inhibitor. Increase of entropy values emphasizes that an increase for the activated complex take place than the reactant with the concentration of the inhibitor. This implies that the reluctance of dissolution of metal increased with the inhibitor concentration, which can be attributed to the considerable intervention of inhibitor molecules during the metallic dissolution.

\section{Electrochemical Impedance Spectroscopic Studies (EIS)}

The corrosion behaviour of $\mathrm{CS}$ in $1 \mathrm{M} \mathrm{HCl}$ with and without inhibitor was examined using impedance spectroscopic analysis at $28^{\circ} \mathrm{C}$. Fig. 4 and 5 represent the Nyquist plots and Bode plots of two Schiff bases A9CNPTDA and ANNPTDA respectively. Impedance parameters including double-layer capacitance $\left(C_{d d}\right)$, solution resistance $\left(R_{s}\right)$ and percentage of inhibition efficiency $\left(\eta_{E I S \%}\right)$ were evaluated from the values of charge transfer resistance $\left(R_{c t}\right)$ and tabulated in Table 3. At both higher and lower frequencies, the capacitance loop intercepts the real axis. These intercepts at the high-frequency end represent the solution resistance $\left(R_{s}\right)$ and at the lower frequency end denote the sum of $R_{s}$ and $R_{c t}$. The difference between these intercepts can be calculated to find out $R_{c t}$ which is a measure of the electron transfer takes place on the exposed metallic surface analysis and is inversely proportional to the corrosion rate of the surface $^{19,20}$. The equivalent circuit that exactly fit the EIS curves generally consisted of a solution resistance $R_{s}$, double-layer capacitance and charge transfer resistance $R_{c t}$ (Fig. 6). Table 1, reveals that as increasing concentration of both inhibitors, $R_{c t}$ values were increased and $C_{d \mid}$ values were decreased.

The variation in $R_{c t}$ values can be explained by the adsorption process by which the inhibition mechanism takes place ${ }^{21}$. As the inhibitor concentration increases there would be a considerable increase in the amount of adsorption process which results in the prevention of the charge transfer of the metal atoms on the metallic surface and solution, which in turn increase the charge transfer resistance. The lowering of $C_{d \mid}$ values with increase in the inhibitor concentration can be associated with the reduction of local dielectric constant values and rise in the thickness of the electrical double layer. These observations testify the inhibitor action at the solution-metal interface. From the data, it is obvious that both Schiff bases A9CNPTDA and ANNPTDA act as potential corrosion inhibitors in hydrochloric acid medium. Maximum efficiency of inhibition 97.90\% was obtained for A9CNPTDA and $92.47 \%$ for ANNPTDA at $1 \mathrm{mM}$ concentration

Table 3: Electrochemical impedance parameters of CS corrosion with and without Schiff bases A9CNPTDA and ANNPTDA in $1 \mathrm{M} \mathrm{HCl}$

\begin{tabular}{ccccc}
\hline Inhibitors & Conc. $(\mathrm{mM})$ & $\left.\mathrm{C}_{\mathrm{dl}}(\mu \mathrm{F} \mathrm{cm})^{2}\right)$ & $\mathrm{R}_{\mathrm{ct}}\left(\Omega \mathrm{cm}^{-2}\right)$ & $\eta_{\mathrm{EIS} \%}$ \\
\hline & Blank & 101 & 16.1 & - \\
& 0.2 & 83.9 & 157 & 89.74 \\
A9CNPTDA & 0.4 & 53.0 & 187 & 91.39 \\
& 0.6 & 45.7 & 239 & 93.23 \\
& 0.8 & 47.5 & 712 & 97.73 \\
\hline \multirow{4}{*}{ ANNPTDA } & 0.4 & 46.0 & 38.8 & 83.50 \\
& 0.6 & 73.1 & 68.6 & 85.09 \\
& 0.8 & 74.9 & 131 & 90.69 \\
& 1.0 & 73.6 & 208 & 92.47 \\
\hline
\end{tabular}

\section{Potentiodynamic Polarization Studies}

Tafel extrapolation analysis and linear polarization studies were conducted to establish the impact of Schiff bases towards the polarization of metal specimens by the determination of polarization resistance, corrosion current density and the percentage of inhibition efficiencies. Tafel and linear polarization curves recorded are represented in Fig. 7 and 8. The corrosion parameterslike corrosion potential $\left(\mathrm{E}_{\text {corr }}\right)$, corrosion current density $\left(\mathrm{I}_{\text {corr }}\right)$, polarization resistance $\left(\mathrm{R}_{\mathrm{p}}\right)$ and inhibition efficiency $\left(\eta_{\text {pol\% }}\right)$ are listed in Table 4. 
Table 4: Potentiodynamic polarization parameters of $\mathrm{CS}$ in the presence and absence of A9CNPTDA and ANNPTDA in $1 \mathrm{M} \mathrm{HCl}$ at $28^{\circ} \mathrm{C}$ for immersion period $30 \mathrm{~min}$

\begin{tabular}{lcccccc}
\hline Inhibitors & $\begin{array}{c}\text { Conc. } \\
(\mathrm{mM})\end{array}$ & $\begin{array}{c}\mathrm{E}_{\text {corr }} \\
(\mathrm{mV} / \mathrm{SCE})\end{array}$ & $\begin{array}{c}l_{\text {corr }} \\
\left(\mu \mathrm{A} / \mathrm{cm}^{2}\right)\end{array}$ & $-\mathrm{bc}$ & ba & $\eta_{\text {pol\% }}$ \\
\hline A9CNPTDA & Blank & 451 & 1115 & 110 & 184 & - \\
& 0.2 & 471 & 77.0 & 70 & 134 & 93.1 \\
& 0.4 & 469 & 37.8 & 63 & 119 & 96.6 \\
& 0.6 & 479 & 36.0 & 61 & 123 & 96.8 \\
& 0.8 & 470 & 30.3 & 66 & 115 & 97.3 \\
\hline & 1.0 & 476 & 12.2 & 52 & 103 & 98.9 \\
& 0.2 & 473 & 492 & 93 & 151 & 55.9 \\
& 0.4 & 468 & 161 & 83 & 153 & 85.7 \\
& 0.6 & 472 & 125 & 73 & 142 & 88.8 \\
& 0.8 & 453 & 105 & 62 & 138 & 90.6 \\
& 1.0 & 483 & 70.4 & 79 & 125 & 93.7 \\
\hline
\end{tabular}

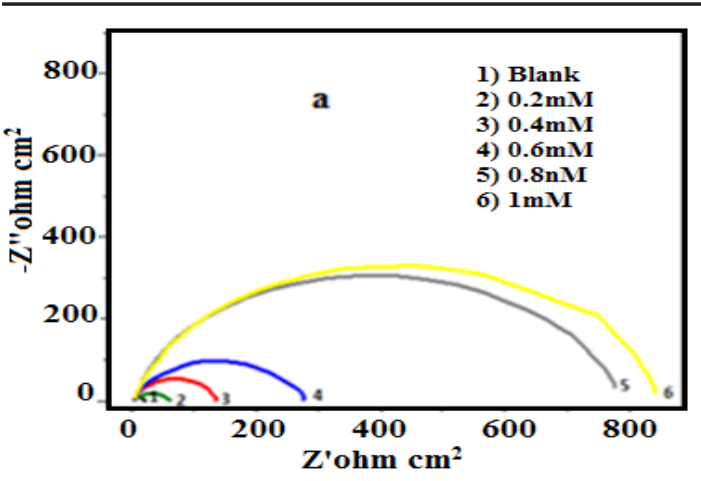

From Tafel data, it is evident even at low concentrations; both the inhibitors possess marked inhibition efficiency in $1 \mathrm{M} \mathrm{HCl}$. The maximum inhibition efficiency of $98.90 \%$ and $93.70 \%$ were respectively shown by A9CNPTDA and ANNPTDA at $1 \mathrm{mM}$ concentration. This is also congruent with the data obtained in gravimetric analysis and EIS measurements. In both cases, the cathodic slopes exhibited predominant changes than the anodic slopes which are a clear evidence for the preferential adsorption of these Schiff bases on the cathodic sites. Furthermore, the $\mathrm{E}_{\text {corr }}$ values were not altered significantly with respect to that of blank and appreciable change was noted in anodic or cathodic slopes in both the Schiff bases suggesting that in $1 \mathrm{M} \mathrm{HCl}$ both Schiff bases behave as mixed-type inhibitors. In other words, the hydrogen evolution process was considerably hindered by both molecule compared to the oxidation of $\mathrm{Fe}$ into $\mathrm{Fe}^{2+}$.

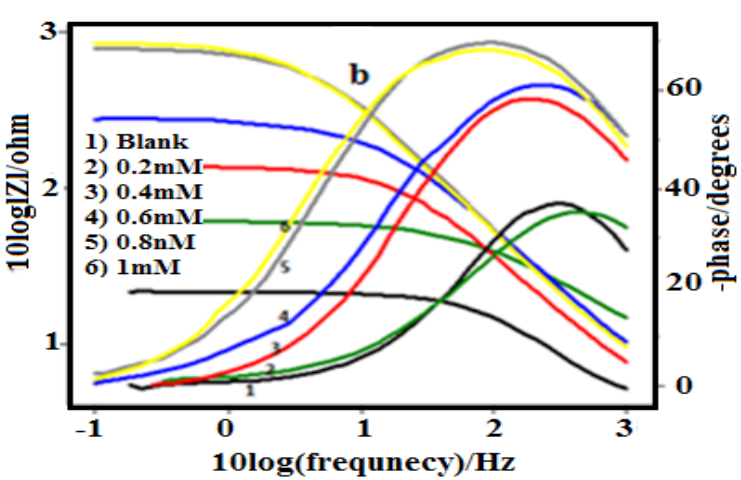

Fig. 4.a) Nyquist plots and b) Bode plots of $C S$ in the presence and absence of A9CNPTDA in1M HCI
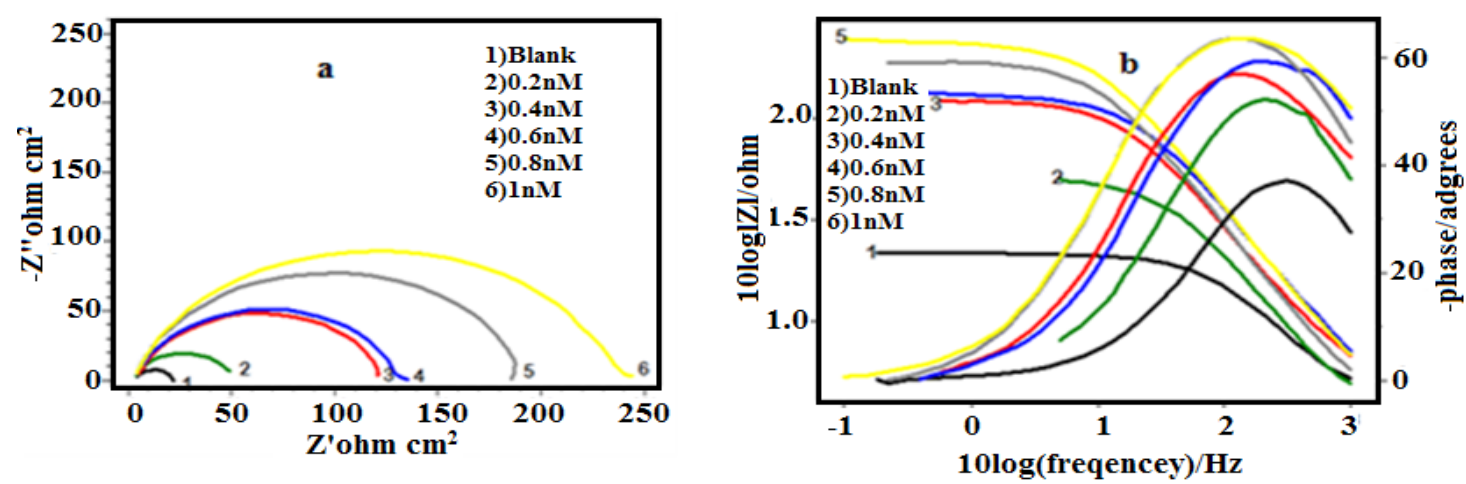

Fig. 5. a) Nyquist plots and b) Bode plots of $\mathrm{CS}$ in the presence and absence of ANNPTDA in 1M HCI

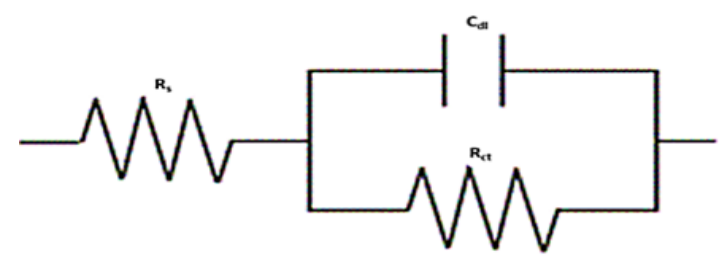

Fig. 6. Randles circuit fitted for EIS measurements

\section{Adsorption Studies}

The mechanism of corrosion inhibition of the Schiff bases understudy was established by the adsorption studies by invoking adsorption isotherms such as Langmuir, Temkin, Frumkin and Freundlich isotherms ${ }^{22-26}$. Evaluation of adsorption parameters is done by selecting the best-fit isotherm model 
assisted by the correlation coefficient $\left(R^{2}\right)$. Both Schiff bases, A9CNPTDA and ANNPTDA obeyed Langmuir adsorption isotherms in $1 \mathrm{M} \mathrm{HCl}$, which can be expressed as

$$
\frac{C}{\theta}=\frac{1}{K_{a d s}}+C
$$

Where $\mathrm{C}$ is the concentration of inhibitor $\theta$ is the fractional surface coverage and Kadsis the value of adsorption equilibrium constant. The

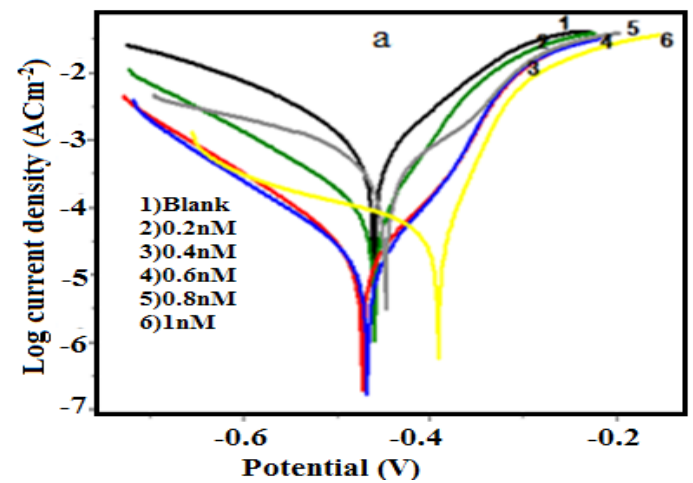

adsorption equilibrium constant, $\mathrm{K}_{\text {ads }}$ mainly depends on the standard free energy of adsorption $\Delta \mathrm{G}^{0}{ }_{\text {ads }}$, by the relation.

$$
\Delta \mathrm{G}_{\text {ads }}^{0}=-\mathrm{RT} \ln \left(55.5 \mathrm{~K}_{\mathrm{ads}}\right)
$$

Where 55.5 is the molar concentration of water, $R$ is the ideal gas constant and $T$ is the temperature in Kelvin. Adsorption parameter values derived are listed in Table 5.

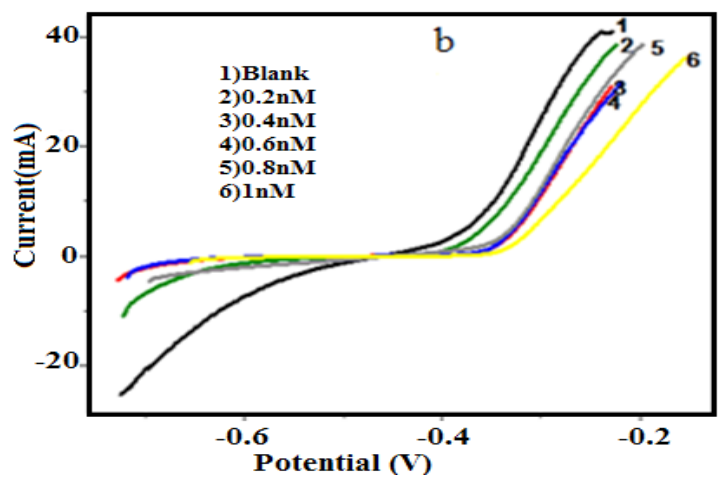

Fig. 7: a) Tafel plots and b) Linear polarization plots for CS in the presence and absenceof A9CNPTDA in 1M HCI
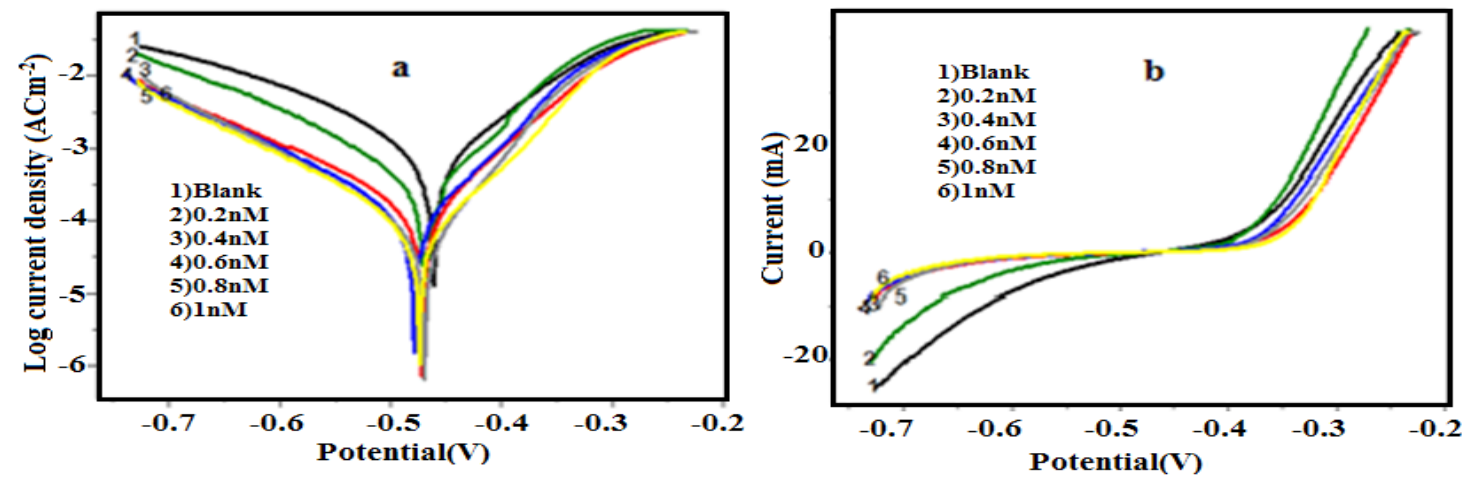

Fig. 8: a) Tafel plots and b) Linear polarization plots for CS in the presence and absence of ANNPTDA in 1M HCl

Table 5: Adsorption parameters of Schiff bases, A9CNPTDA and ANNPTDA on CS surface in $1 \mathrm{M} \mathrm{HCl}$

\begin{tabular}{ccc}
\hline Thermodynamic parameter & A9CNPTA & ANNPTDA \\
\hline $\mathrm{K}_{\text {ads }}$ & 58823.5 & 22222.2 \\
$\Delta \mathrm{G}_{\text {ads }}^{0}(\mathrm{KJ} / \mathrm{mol})$ & -37.56 & -35.12 \\
\hline
\end{tabular}

Data reveal that A9CNPTDA has comparatively high Kads value than ANNPTDA which establishes the greater efficiency of adsorption of A9CNPTDA over ANNPTDA. The $\Delta \mathrm{G}^{0}$ ads values obtained for A9CNPTDA and ANNPTDA are -37.56 and $-35.12 \mathrm{KJ} / \mathrm{mol}$ respectively. The $\Delta \mathrm{G}^{0}$ ads values up to $-20 \mathrm{~kJ} \mathrm{~mol}^{-1}$ indicates clearly of the electrostatic attraction or physisorption between the charged molecule and charged metal surface whereas those more negative than $-40 \mathrm{~kJ} \mathrm{~mol}^{-1}$ indicates the strong adsorption of the inhibitors on the metallic surface through strong co-ordinate bonds or chemisorptions. In the present study, both inhibitors exhibit $\Delta \mathrm{G}^{0}$ values between $-20 \mathrm{~kJ} \mathrm{~mol}^{-1}$ and $-40 \mathrm{~kJ} \mathrm{~mol}^{-1}$ which indicates that the absorption behaviour of the inhibitors involves both chemical and electrostatic interaction.

\section{Surface Morphological Studies}

Surface morphology of the metal surfaces was evaluated with the aid of SEM analysis ${ }^{27,28}$. Fig. 10(a)-10(d), respectively, show the magnified surface images of bare metal, metal immersed in acid and metal treated with acid in the presence 
of A9CNPTDA and ANNPTDA (1 $\mathrm{mM}$ ) for 24 hours. The pits and cracks appearing in the SEM image of the bare metal specimen were due to the polishing effects. The SEM image of a blank specimen appeared to be very rough due to severe corrosion. Comparatively smoother images were displayed by metal specimens immersed in $1 \mathrm{M} \mathrm{HCl}$ in the presence of A9CNPTDA and ANNPTDA at $1 \mathrm{mM}$ concentration and the textures of all surface images showed considerable differences. This can be attributed to the prevention of CS corrosion in acid by the adsorption of molecules.

\section{Quantum Chemical Studies}

The corrosion inhibition response of organic molecules can be correlated with the energy of frontier molecular orbitals. The donor-acceptor interactions (HSAB concept) between the filled molecular orbitals of the inhibitor molecules and the vacant d-orbitals of $\mathrm{Fe}$ atoms on the surface are very important in the prevention of metal dissolution.

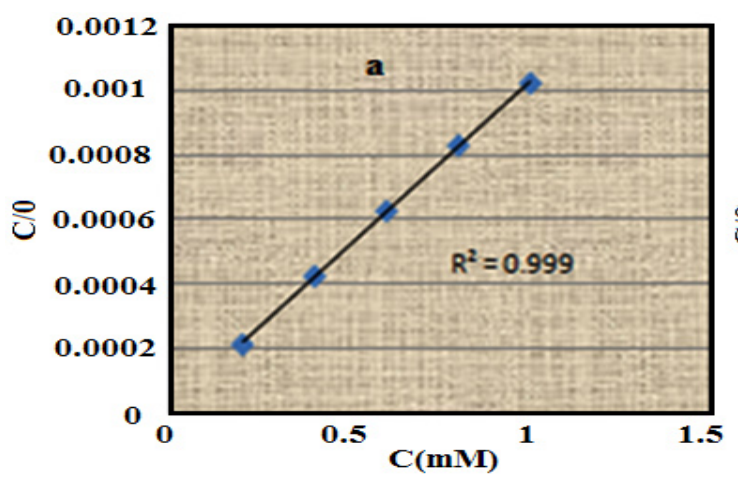

The highest value of $\mathrm{E}_{\text {номо }}$ and the lowest value of $E_{\text {LUMO }}$ and the energy difference between the HOMO and the LUMO $(\Delta \mathrm{E})$ are the important quantum chemical parameters which facilitate the strong binding of the molecule on the metal surface. Optimisations of geometry and quantum chemical calculations were performed by DFT method using GAMMES software. B3LYP method was employed in DFT calculations ${ }^{29,30}$. Fig. 11 shows HOMO and LUMO for the studied compounds. Since HOMO is spread throughout the compound, it is necessary to examine the coefficients of the HOMO for better understanding. The coefficient values give the information about the atomic orbital with the highest contribution and therefore the atom that has the highest tendency to donate electrons. The LUMO is the unoccupied orbital that has the lowest energy and gives information and gives information about the regions in a molecule which has the highest tendency to accept electrons from an electron-rich species.

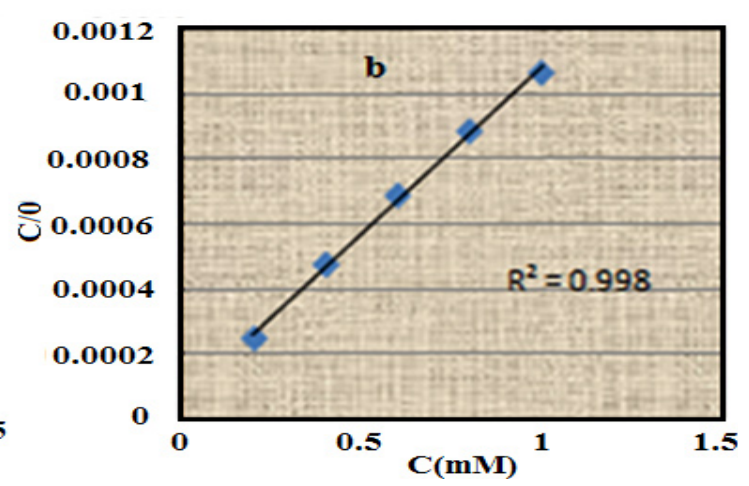

Fig. 9. Langmuir adsorption isotherms for (a) A9CNPTDA and (b) ANNPTDA on CS in $1 \mathrm{M} \mathrm{HCl}$
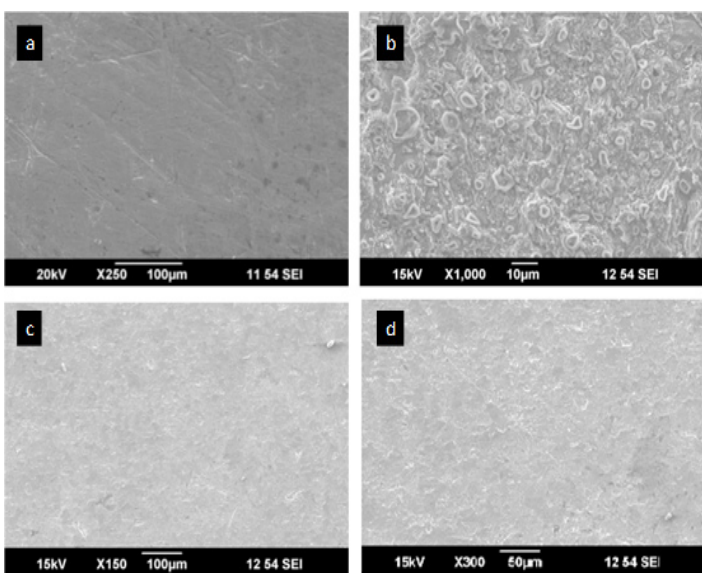

Fig. 10. SEM images of (a) bare CS (b) CS treated with $1 \mathrm{M}$ $\mathrm{HCl}$ (c) CS treated with A9CNPTDA(1 mM) (d) CS treated with ANNPTDA(1 $\mathrm{mM})$ for 24 hours

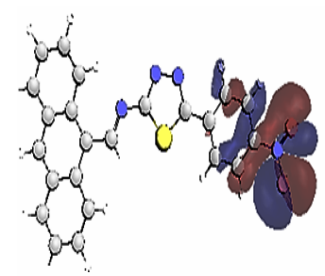

HOMO of

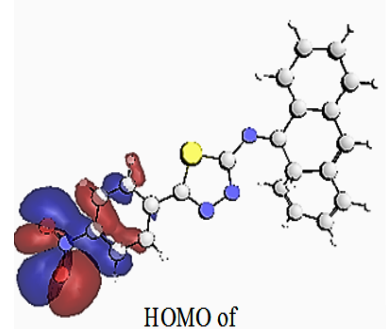

Fig. 11. HOMO and LUMO of A9CNPTDA and ANNPTDA 
Table 6: Quantum chemical parameters of A9CNPTDA and ANNPTDA

\begin{tabular}{llllllll}
\hline Schiff base & $\mathrm{E}_{\text {номо }}(\mathrm{eV})$ & $\mathrm{E}_{\text {Luмо }}(\mathrm{eV})$ & $\Delta \mathrm{E}$ & $\chi$ & $\eta$ & $\Delta \mathrm{N}$ \\
\hline A9CNPTDA & -3.530 & -0.8435 & 2.68 & 2.204 & 1.361 & 0.836 \\
ANNPTDA & -3.565 & -0.5442 & 3.02 & 2.041 & 1.497 & 0.815 \\
\hline
\end{tabular}

The energy of the HOMO $\left(\mathrm{E}_{\text {номо }}\right)$ provides information about the tendency of a molecule to donate electrons to an electron-poor species. The higher the $\mathrm{E}_{\text {номо }}$, the greater is the tendency of a molecule to donate its electrons to the electronpoor species. Therefore a comparison of the $\mathrm{E}_{\text {номо }}$ of the studied compounds obeys the order, A9CNPTDA>ANNPTDA, which is in full accordance with the order of inhibition efficiency which implies that A9CNPTDA has highest tendency to donate its electrons to the metal surface and therefore binds strongly on the metal surface.

The energy gap between the frontier orbitals $\Delta \mathrm{E}$ is usually very important to describe the static molecular reactivity. In this way, low values of $\Delta \mathrm{E}$ imply that the polarization and the adsorption of the molecule on the metal surface is much easy. However, as it is shown in Table 6, A9CNPTDA exhibits a smaller $\triangle \mathrm{E}(2.68 \mathrm{eV})$ than ANNPTDA $(3.02 \mathrm{eV})$, indicating the high ability to accept electrons from the d-orbital of iron and high stability of the $[\mathrm{Fe}-\mathrm{L}]$ complexes

The number of electrons transferred $(\Delta N)$ indicates the tendency of a molecule to donate electrons. The higher the value of $\Delta \mathrm{N}$, the greater is the tendency of a molecule to donate electrons to the electron-poor species. In the case of corrosion inhibitors, a higher $\Delta \mathrm{N}$ implies a greater tendency to interact with the metal surface through the adsorption process and A9CNPTDA has relatively $\Delta N$ value. According to Lukovits $^{31,32}$, if $\Delta N<3.6$, the inhibition efficiency is increased with increasing electron-donating ability at the steel surface. In this study, synthesised inhibitors were the donor of electrons, and the metal surface was the acceptor. This result supports the assertion that the adsorption of inhibitors on the steel surface can occur based on donor-acceptor interactions between the $\pi$ electrons of the compound and the vacant d-orbitals of the metal surface. The essential effect of inhibitors is due to the presence of free electron pairs in the $\mathrm{N}$ and $S$ atoms, p-electrons on the aromatic ring, type of interaction with the steel surface, and metallic complexes formation. It is well known that steel has potential coordination affinity towards $\mathrm{N}$ and $S$ donors Schiff bases. Therefore, adsorption on the metal surface can be ascribed to coordination through heteroatoms and $\pi$-electrons of aromatic rings $^{33}$. In the present case, synthesized inhibitors have unshared electron pairs on $\mathrm{N}$ and $\mathrm{S}$ which enable them to form coordination with steel.

\section{CONCLUSION}

Two novel polynuclear Schiff bases A9CNPTDA and ANNPTDA are very effective corrosion inhibitors for $\mathrm{CS}$ in $\mathrm{HCl}$ medium. The inhibition efficiency of both Schiff bases was exceeded $95 \%$, which may be due to the presence of highly polarisable 'S'atom, lone pair of electrons on $\mathrm{N}$ atom, aromatic rings and azomethine linkage etc; All corrosion monitoring studies revealed that the inhibition efficiency of ANNPTDA is lower than that of A9CNPTDA at all concentrations. It may be due to the presence of strained azomethine linkage, relatively less aromatic behaviour and slight deviation from the coplanarity may be attributed to the decreased inhibition efficiency of ANNPTDA. Both inhibitors obeyed Langmuir adsorption isotherm on the CS surface during the inhibition process. The inhibitors delay the process of corrosion by hindering the cathodic process mainly. Quantum chemical studies differentiated the protective power of molecules against CS corrosion. Surface analysis using SEM portrayed the anticorrosive capacity of inhibitors.

\section{ACKNOWLEDGEMENT}

The authors are grateful to SAIF-STIC, Cochin University of science and technology for their valuable support.

\section{Conflicts of Interest}

The authors declare no conflict of interest.

\section{REFERENCES}

1. Agrawal, R.;Namboodhri T.K.G. Corros. Sci., 1990, 30, 37-52.

2. Sekine, I.A.;Masuko, A.; Senoo, K. Corros.

Sci., 1987, 43, 553-562.

3. Quraishi, M.A.; Khan, M.A.W.; Ajmal, M. AntiCorros. Methods Mater., 1996, 43, 5-21. 
4. Murlidharan, S.;lyer S.V.K. Anti-Corros. Methods Mater., 1997, 44, 100-118.

5. Al-Andis, N.; Khamis, E.; Al-Mayouf, H.; Aboul, B. Corros. Prev. Control., 1995, 42, 13-25.

6. Hammouti, B.; Aouniti, M.;Taleb; Brighli, M.; Kertit, S.; Corrosion., 1995, 51, 441-461.

7. Begum, A.S.; Nalini, D.; and Devi, T.M. Orient. J. Chem., 2010, 26(4), 1333-1343.

8. Bhagat,S.M; Bhagat,T.M; Unchandkar,A.R; Deshpande, M.N.; Orient. J. Chem., 2010, 26(4), 1545-1548.

9. Bhagat, S.M.; Kolhatkar, D.G.; Anchdkar,A.R.; and Deshpande, M. N. Orient. J. Chem., 2010, 26(4), 649-653.

10. Begum, A.S.; Nalini, D.; Suvarnna,K. Orient. J. Chem., 2010, 26(3), 891-900.

11. Deng, S; Li, X; Fu, H. Corros. Sci., 2011, 53, 3704-3711.

12. Emregul, K.C; Atakol,O. Mater. Chem. Phys., 2004, 83, 373-379.

13. Musa, A.Y; Kadhum, A.A.H.; Mohamad, A. B.; Takriff, M. S. Corros. Sci., 2010, 52(10), 3331-3340.

14. Ashassi-Sorkhabi, $\mathrm{H}$; Shaabani, B; Seifzadeh, D. Electrochem. Acta., 2005, 50, 3446-3452.

15. Bentiss,F.; Lagrenee, M.; Traisnel, M.; Hornez, J. C. Corrosion., 1999, 55(10), 968-976.

16. Reza Soleymani, Khalil Ghesmat-Konandeh, Reihaneh Dehghanian Dijvejin, Orient. J. Chem., 2012, 28(3), 1331-1346.

17. Reza Soleymani, Sahar Farsi-Madan, Khalil Ghesmat-Konandeh. Orient. J. Chem., 2012, 28 (2), 703-715.

18. Reza Soleymani, Yasin Mohammad Salehi, Tahereh Yousofzad, Maryam Karimi-Cheshmeh
Ali. Orient. J. Chem., 2012, 28 (2), 627-643.

19. Yurt, A.;Balaban, A.; Kandemir, S.U.; Bereket, G.; Erk, B. Mater. Chem. Phys., 2004, 85, 420-426.

20. McCafferty, M.; Hackerman, N.; J. Electrochem. Soc., 1972, 119, 146-154.

21. Azhar, M.E.; Mernari, B.; Traisnel, M.; Bentiss, F.; Lagrenee, M. Corros. Sci., 2001, 43, 2229-2238.

22. Cottis, R.A; Al-Awadhi, H.; Al-Mazeedi; Turgoose, S. Electrochem.Acta., 2001, 46 (24), 3665-3674.

23. Hamani, H.;Douadi, T.; Daoud, D.; Al-Noaimi, M.; Chafaa, S.; Measurement., 2016, 94, 837-846

24. Ateya, B.G; El-Anadouli, B.E; El-Nizamy, F.M, Corros. Sci., 1984, 24(6), 509-515.

25. Zhao, T.; Mu, G, Corros. Sci., 1999, 41(10), 1937-1944.

26. Soltani, N, Salavati, H, Rasouli, N, Paziresh, M, Moghadasi, A. Chem. Eng. Com., 2016, 203(6), 840-854.

27. PalayoorV.R.;Kakkassery, J.T.; Kanimangalath S.S.; Varghese S. Int. J. Ind.Chem., 2017, 8(1), 49-60.

28. Ashassi-Sorkhabi, H, Shaabani, B, Seifzadeh D. Appl.Surf.Sci., 2005, 239(2), 154-164.

29. Sastri,V.S.; Perumareddi, J.R.; Corrosion., 1997, 3(8), 617-22.

30. Senet.P.; Chem. Phys. Lett., 1997, 275(5), 527-532.

31. Lukovits, I.; Kalman, E.; Zucchi, F, Corrosion., 2001, 7(1), 3-8.

32. Li, L.; Zhang, X.; Lei, J.; He, J.; Zhang, S.; Pan, F.; Corros. Sci., 2012, 63, 82-90.

33. Zheng, X.; Zhang, S.; Li, W.; Gong, M.; Yin, L.; Corros. Sci., 2015, 95, 168-179. 